\title{
Feederism: Transgressive Behavior or Same Old Patriarchal Sex?
}

\author{
Ariane Prohaska \\ Correspondence: Ariane Prohaska, Department of Criminal Justice, The University of Alabama, Tuscaloosa, AL \\ 35487-0320, USA. Tel: 1-205-348-7265. E-mail: aprohaska@bama.ua.edu
}

\author{
Received: March 21, 2013 Accepted: April 10, 2013 Available online: June 5, 2013 \\ doi:10.11114/ijsss.v1i2.105 \\ URL: http://dx.doi.org/10.11114/ijsss.v1i2.105
}

\begin{abstract}
In this paper, I review the sparse scholarship on feederism, a behavior that involves one partner encouraging or participating in the process of the other partner's weight gain. The desired goal for one of both partners is sexual pleasure, either through the process of weight gain or as a result of the attraction to fat. I also discuss the results of a content analysis of feederism-related websites. My focus here is feederism in heterosexual relationships. I conclude that feederism takes many forms, and although it has been classified as a transgressive sexual behavior, it usually mimics patriarchal sex in the process. At its extreme, feederism is an abusive behavior dangerous to the partner (usually the woman) who desires to gain weight as quickly as possible. Suggestions for further research are given.
\end{abstract}

Keywords: feederism, patriarchy, sexual fantasy, erotic weight gain, gender inequality

\section{Introduction}

A relatively new literature on online communities has documented the existence of groups for individuals who participate in stigmatized behaviors, such as polyamory and bestiality (Lillie, 2004) or bug chasing (Gauthier and Forsyth, 1999), among others. These websites are not just meeting places for existing group members; they also act as recruitment tools. Curious web browsers who accidentally stumble upon one of these sites may become the newest members of these underground groups (Durkin, Forsythand Quinn, 2006; Quinn and Forsyth 2005).

Another relatively unknown behavior that has gained a following on the internet is feederism. This behavior has been criticized by fat advocates and feminists alike. According to the National Association for the Advancement of Fat Acceptance (NAAFA), feederism is a behavior that involves one partner encouraging or participating in the process of the other partner's weight gain. The desired goal for one of both partners is sexual pleasure, either through the process of weight gain or as a result of the attraction to fat. In most cases, at least in heterosexual relationships, feeders or encouragers are men, and feedees or gainers are women (Bestard, 2008). NAAFA has taken a stance against feederism, advocating that "people of all sizes become empowered to demand respect for their bodies in the content of sexual relationships, without attempting to lose or gain weight in order to win a partner's approval or attract or retain that partner's desire" (National Association to Advance Fat Acceptance 2011). NAAFA believes that feederism is a behavior based on power on the part of the feeder only, and that this coercive relationship is demeaning to people of size. The fat acceptance community has a strong presence on the internet, but there are disagreements among its members on if feederism is just a sexual fetish or if it is a destructive behavior.

Writings on feederism have characterized it as a stigmatized lifestyle choice (Bestard, 2008), pornography (Hester, 2009) or an abusive relationship (Murray, 2004). In turn, research has not concluded if the internet is liberating women of size, or if it is just another form of patriarchal sex. On one hand, some cyber feminists, called cybertopian feminists, argue that liberation is possible on the internet because the user is free from structural constraints (e.g. race, gender), and users can explore new identities and sexualities anonymously (Morohan-Martin, 2000). For example, Sadie Plant (1997) argues that technology will eventually eliminate gender distinctions, challenging and eradicating masculinity as we know it. On the other hand, dystopian cyber feminists argue that women will be constrained by the norms of the offline society while online (Brophy, 2010). Users of the web still have gender, race, ability, and size, and experience life according to these statuses in offline society; in fact, one's body is what enables her to use the internet. Further, this branch of cyber feminism argues that the internet is patriarchal, and women on the net will be exploited just as they are offline. According 
to Johnson (1997), patriarchal sex involves the objectification of women for the ultimate goal of conquest. Or, put more bluntly, "patriarchal sex is fucking" (Jensen, 1997, p. 5). The sexual act itself is secondary; thus, women are a means to an end of achieving hegemonic masculinity. In the contemporary United States, hegemonic masculinity is rooted in patriarchal ideals such as control, power, competition, aggression, the devaluation of emotional attachment, and, especially, the oppression of women (Johnson, 1997).

Research has not yet discovered if the web allows women to explore alternative forms of sexuality such as feederism liberated from societal norms of fat bashing and the de-sexing of women of size. On the other hand, these websites may just be showing fat women in ways that perpetuate hegemonic ideas about both women of size and heterosexual sex.

Although one study has discussed feederism from the perspective of those who participate in the behavior (Bestard 2008), no studies have examined the vast amount of content on the internet that discusses and/or depicts feederism. By analyzing these websites, one can get a better (although not perfect) idea about all of the ways in which feederism takes form and how feederism is viewed by those who participate in it as well as those outside of this community. In this paper, I review the small amount of literature on feederism, as well as discuss the results of a content analysis on feederism-related websites. My focus here is feederism in heterosexual relationships. I discuss my findings using perspectives on cyber feminism and masculinity and sex.

\section{Literature Review}

The few writings on feederism range from extremely critical theoretical pieces to empirical research discussing the stigma that feeders and feedees experience, mostly as closeted members of online communities. On one hand, Murray defines feederism as "an underground sexual practice that involves women who allow themselves to be force-fed through a funnel by a dominant male master, who derives sexual excitement from watching his submissive servant grow fatter as he forces her to eat more and more" (2004: 244). Murray, citing Blank (2000) mentions that oftentimes, feeding, or "erotic weight gain", leads to immobilization; the feedee cannot move, and literally cannot leave the relationship. Murray (2004) believes that women of size "choose" feederism because they've been subjected to prejudice and discrimination all of their lives until finding this niche, where they can suddenly be appreciated by the opposite sex. Patriarchal norms of power and control are ever-present in these descriptions of feederism.

Similarly, Halloran (2004) discussed feederism as an "eating fetish", as described by Cameron Mannheim in her book Wake Up, I'm Fat! According to Halloran, Mannheim's description of and feelings about feederism were without critical insight, and this insinuates to the reader that feederism is obviously a problematic behavior. On the other hand, Hester argues that feeding pornography, a genre that involves a camera focusing on a woman's belly while she eats food and is dressed in little clothing, is "one of the most transgressive behaviors available to the modern woman", because it depicts the usually de-sexed fat woman obtaining pleasure without a man present (2009: 37). Yet, she argues, the process of feeding porn still usually involves the man encouraging the woman to immobility, leading to complete dependence on her feeding partner. Later, Hester describes feederism as just another form of traditional pornography, only with different sized women being objectified and controlled by men.

Although the previous articles attempt to explain feederism, there has only been one empirical study on the behavior. Using a symbolic interaction framework, Bestard (2008) studied feederism by interviewing 17 men and 13 women who participated in the behavior, looking particularly at the stigma felt by the members of the community. She allowed her subjects to define what the practice meant to them and how it affected their daily lives. Her definition is broader: "a phenomenon that involves people who are sexually aroused by thoughts and actions having to do with weight gain" (p.2). Bestard found that women were not always the submissives, although most of the time this seemed to be true. Also, feederism did not have to mean eating to immobility, her subjects explained. The women Bestard interviewed emphasized their agency in their relationships; they chose to participate in the behaviors. Men she interviewed were quick to point out that they were not interested in immobility, and that was just a fringe behavior in the feederism community. Bestard also distinguished feeders from encouragers, who do not force-feed their partners but verbally support their partners or cook for them as they strive to gain weight. She also discussed the role of fantasy in erotic weight gain as described by her interview subjects. Many members of the community asserted that they merely fantasized about weight gain and posted stories and art depicting these fantasies on feederism websites.

Most of Bestard's (2008) subjects felt the need to keep their behaviors a secret to family members and other significant people in their offline lives. But online, feeders and feedees felt they had a safe place to discuss their lifestyles free of stigma. Bestard discussed the two most frequented and mainstream websites for the feederism 
community, FantasyFeeder.com and Dimensions.com's erotic weight gain forum, which allow interested parties to access information on how to best gain weight, to chat with other members of the community, to find potential partners, to browse photos and videos of individuals in the process of weight gain, and to obtain support from others (Bestard 2008). These sites, which require users to login with a password, also allow people to share their experiences and photos, and even write fictional accounts of or post art depicting weight gain, which may be sexually arousing to many members of the group. Bestard's (2008) interviews resulted in the creation of a continuum of feederism, ranging from sexual fantasies about feederism (browsing websites, writing fiction, perusing photos and videos) to immobility (feeding to the point of extreme obesity). (Figure 1)

What is unknown is how common each component of feederism is, and if there are more aspects to the behavior that her informants did not discuss. Because feederism is a stigmatized behavior, it is likely difficult to "count" the number of people who are involved in the behavior, and it is possible that those interviewed did not discuss more extreme forms of feederism because of the fear of further stigmatization. Yet because of the online presence of the behavior, we can examine the representations of feederism on the internet. If feederism is an innocent fetish, involving the attraction to fat or involving food in sexual acts, and is consented toby adults (according to most of Bestard's subjects), why is most of the scholarly work about feederism focused on the exploitation of women feedees? Websites about feederism, including groups that provide advice or support, and other sites housing photos and videos of feedees, can help us assess the big picture. My goals for this study are to first analyze how feederism is represented on websites. Is feederism mostly viewed as a sexual fantasy, pornography, a consensual behavior, or forcible feeding. Second, I will situate feederism into past theoretical and empirical work on similarly stigmatized sexual behaviors, focusing on theories of hegemonic masculinity and cyber feminism.

\section{Method}

I use content analysis to analyze websites that contain feederism content. Specifically, I focus on describing the main type of content on that site (e.g. is it a support group, a personal ad, an advice website) and if the discourse on the sites reflects liberation from normative sexual expectations or if it reinforces patriarchal ideas about fat women and sex. Thus, I both look for emerging themes (type of website) and also analyze the websitesin the contexts of the competing cyber feminist perspectives defined above. To gather my sample, I performed internet searches for the following terms: feederism, feedee, feeder, feeding, force feeding, and erotic weight gain during the period of June 2009- June 2010. Many of the sites that appeared as the result of these searches housed links to other websites that discussed or depicted feederism, and these were also included. For the purposes of this paper, I exclude feederism in the gay community, because I am focusing on the patriarchy in heterosexual relationships. If it was not clear if the website was meant for heterosexuals, I excluded the website in my analysis. In total, I found 152 links to websites depicting some aspect of feederism and include all of them in this paper. I used Bestard's continuum of feederism, which ranges from fantasy, to encouragers, to feeders, to immobility (death), to guide my analysis. However, there is much overlap on the websites, which resulted in the creation of broader categories, in and below discuss the components of the continuum of feederism in each category. These categories are: 1 ) websites for feederism groups $(\mathrm{n}=64)$, which were similar to the sites FantasyFeeder.com and Dimensions.com that Bestard described, with posts including photos, self-help, personal ads, etc.; 2) websites with fantasy content $(\mathrm{n}=21)$, which housed either fantasy fiction or feederism art; 3 ) websites defining feederism neutrally ( $\mathrm{n}=18$ ), without encouraging or criticizing the behavior; 4) websites containing personal ads only $(\mathrm{n}=19) ; 5)$ websites containing advice about feederism and weight gain $(\mathrm{n}=16) ; 6)$ websites with pornographic photos only $(\mathrm{n}=15) ; 7)$ websites with videos depicting feederism only $(\mathrm{n}=14)$; websites with articles/comments written in support of feederism $(\mathrm{n}=10)$; and 8 ) websites with articles/comments criticizing the behavior. A more detailed discussion follows.

\section{Results}

\subsection{Feederism Groups}

Group sites (mostly Yahoo! Groups) most often pictured women in their underwear who had large bellies. The majority of these groups attracted "fat admirers" (FAs) who are usually identified as men who are attracted to women of size. Fat admirers may just be attracted to people of size; it is not necessary that an FA be interested in feederism (although feeders are a subset of FAs). On only two of these group websites were men depicted as feedees or gainers; women were described or depicted on all others. Although I was able to join a few of these groups easily, most sites asked for a picture and/or why one wanted to be a member before one could gain access to site materials. I was ignored by all of these groups; in fact, when I joined the two most popular sites (Dimensions.com and FantasyFeeder.com) and attempted to contact members for interviews, my posts were 
twice deleted from discussion groups, possibly because of distrust of outsiders (in this case, a researcher) who they may feel to be judgmental (Note 1). Despite not being able to see premium content on many of the group sites, descriptions of the site were visible to non-members before entering. A typical description of a feederism group follows:

This a group for genuine FAs, male or female, who enjoy huge bellies, weight gain fantasy, "fat Talk", and other topics related to being a fat admirer/fat fetishist. If big bellies, cellulite and huge rolls of blubber turn you on, this is the right place to discuss it. My fat wife enjoys my fetish, too, and would love to read some comments on how fat she is...PLEASE TELL ME WHY YOU WANT TO JOIN or your application will be denied. (http:?/groups.yahoo.com/group/fat_belly_talk/summary)

As mentioned earlier, the groups are likely private because of the stigma members may feel from the outside world. Bestard's (2008) interviewees echoed these sentiments. Group members have found a safe place guarded from the fat-phobic world, a place where they can be themselves and not worry about being judged. Yet the closed environment may also lead to public presumptions about feederism as well, such as that feederism is only about force-feeding and extreme weight gains, as noted by the feminists discussed above.

Another typical description of feederism groups describes the categories that women are placed into based on their size, so that onlookers can browse the photos of the women that they find the most desirable. One group was described as "a group for those who enjoy any kind of woman. If it is big breasts, bellies, booty, and even bbw and weight gaining women" (http:/groups.yahoo.com/group/FAsandSSBBWSonly/summary). Another site (http://groups.yahoo.com/gruop/feederismplace/summary) says "please only pics of women 250 pounds or more." Most of these sites ask for pictures of women to be perused by male viewers. Less typical are groups describing immobility, such as a group "dedicated to uniting feedees and feeders in the act of sensual feeding. Encouraging one's mate to eat and gorge until she is utterly immobile" (http://groups.yahoo.com/group/FEEDEE_N_FEEDERLOVINGSSSBBW/?tab=s).

Immobility was always discussed as an option for the women in the group. Bestard's (2008) interviewees often explained this as a result of the $\mathrm{D} / \mathrm{S}$ (Dominant/Submissive) culture within feederism. Yet this explanation seems simplified in lieu of a discussion on heterosexual sex and power. Despite the discussion of immobility, these group websites generally described feederism as just another fetish for consenting adults.

\subsection{Fantasy Websites}

A sexual fantasy can refer to "any mental imagery that is sexually arousing or erotic to the individual" (Leitenbergand Henning, 1995: 70). A very large number of websites I found contained fictional stories about weight gain, or feederism fiction. These stories were mostly about heterosexual couples engaging in feeder/feedee or encourager/gainer relationships. One story discussed a 2500 pound man and his happiness reaching his goal weight. Some Yahoo! Groups linked to fantasy fiction as well, but were also kept private to members of the group. Yet other fantasy websites were links to art, mostly cartoon drawings, usually of women. Some of these sites housed drawings of women weighing 1,000 pounds or more eating food. One drawing depicted Meg Griffin of television's animated sitcom "Family Guy" as a gainer.

These websites warrant questions about what fantasies mean in the real world. Do some people really wish they could have a partner who is 1,000 pounds? Do some gainers wish they could weigh 2,500 pounds? Howitt (1995) argues that fantasy and reality are in fact separate in most individual's lives. Yet he also claims (2004) that fantasy may arise out of experience, as a result of his study of sex offenders whose experiences may have been a "blueprint" for their subsequent criminal behavior. However, Leitenberg and Henning (1995) are quick to assert that fantasy does not always cause a behavior to occur, even among the most deviant fantasies (e.g. rape, pedophilia).

Some of Bestard's (2008) subjects note that fantasy fiction and art exist because people are respectful of the limitations of the human body or because one may not have a partner with whom they can participate in feederism. Perhaps some fantasy writers feel trapped by society's weight expectations and feel an escape in feederism fiction. Bestard defines immobility as weighing $500 \mathrm{lbs}$ or more, which is clearly less than the men and women in feederism fantasies usually weigh. For the most part, the fantasy websites did not give the impression that fantasy leads to more destructive feederism behaviors. Further research is needed on fantasy feederism fiction and art before drawing more conclusions about the link between fantasy and reality.

\subsection{Personal Ads}

For the most part, feederism personal ads involved male feeders looking for female feedees. One typical ad read, "I am looking for a gluttonous babe who is all about food and will push herself to the limit to make me happy. 
Role-Playing is on the table" (http://groups.yahoo.coms/grou/subsgettingfatter/). Yet there were a few women looking for feedee men. One of these ads, entitled "Decent Man for Sweet SSBBW", stated, "I like to cook, love to eat, love to feed my loved one's. A feedee would be perfect for me. I know it!" (http://www.foodloverspassions.com/desearch/search.html?keywords=feedee)

Yet another type of personal ad involved women asking for men to be their feeders. Bambi wrote in her personal ad that she liked being humiliated and degraded, as well as fed. A picture of her is shown with the ad (http://www.geocities.com/bambi_feedee_sub/index.html). She is in a wheelchair, and she wishes to be immobile.

Ads like Bambi's center on issue of choice. It appears that women such as Bambi are choosing to be feedees, bringing up the argument that feederism is a "lifestyle choice". Bestard's (2008) subjects reiterate this point often in interviews. "Rosie" states, "I think of a 'lifestyle' as an everyday expression of one's character. When we take our identity and weave it into our daily life, that's a lifestyle. So, to the extent that I express myself outwardly as a gainer, feederism is a lifestyle for me" (Bestard, 2008: 83). However, like the woman who "chooses" to be a waitress or a sex worker, barriers to other life options may result in the "choice" to want a partner to make her immobile. Patriarchal structures produce barriers to women's economic success (Johnson, 1997), and women have fewer opportunities for success by culturally normative means. A woman who does not fit ideal beauty standards may find success being a submissive partner for a fat admirer feeder, echoing Hester's (2009) ideas about feederism. These women may be happy to have found a niche in the feederism community, may be accepted for their size if they maintain a submissive attitude and role in their relationships. So, as Hester suggests, heterosexual sex in feederism is still patriarchal, but its victims are fat women.

A similar "choice" argument has been debated by feminists discussing sadomasochism (Hopkins, 1994). Because both sadomasochism and feederism can involve physical harm when limits are tested, a comparison can be made between the two behaviors. Hopkins writes that some radical feminists believe that internalization of patriarchal values does not mean that one is consenting to abuse; "consent" is merely a result of the oppressive nature of patriarchy. Thus, in $\mathrm{D} / \mathrm{S}$ culture, consent is "either a structural impossibility...or a hopelessly conflated irrelevancy" (p. 119). Yet Hopkins argues that sadomasochism is not always replication of patriarchy; rather, sadomasochism is a simulation of patriarchy. It is a gender performance that has been scripted between two consenting adults. For Hopkins, the desire of the dominant partner may not be to hurt someone; rather, the desire may be to participate in simulation, or the performance. He clarifies this difference between replication and simulation by discussing a roller coaster ride:

...the experience desired by the roller coaster rider is precisely the simulation of those lethal experiences- not because the simulation is all she can get, but because the simulation itself is thrilling and satisfying. There is no actual desire to die, fall, or crash. So in the same way the roller coaster rider may find actually falling to her death repugnant and horrible, but finds the simulation of the event thrilling and exciting, the SM practitioner may find humiliation repugnant and horrible, but finds the simulation of that event thrilling and exciting-not as a stand-in but as a goal in itself (Hopkins, 1994:126).

Hopkins' analysis can be applied to feederism as a "choice". First and foremost, feederism involves rapid weight gain, which can cause physical harm to the feedee. In fact, feederism has been called abuse by critics (Murray, 2004) because of the physical limits that the behavior tests. So, has the feedee internalized patriarchy or is she just enjoying the act or the fantasy, welcoming the risk? Is there a point when enjoying the fantasy is too much of a risk? Does there have to be a desire for one to die for death to occur? What if the simulation goes wrong? With extreme feeding, by the time the feeder or the feedee realizes the activity has gone too far, it may be too late to utter a safe word. These behaviors are extremely dangerous and one false move can lead to injury or death. Extreme feeding and its consequences will be discussed in more detail when the "how-to" websites are highlighted later in this paper. However, personal ads, for the most part, depicted women and submissives willing to go to extremes for their partners, reflecting dystopian cyber feminist ideas.

\subsection{Informational Websites/Definitions of Feederism}

Informational websites, blogs, and blog posts discuss feederism neutrally; no opinion is given on the matter. These sites inform the general public about the behavior, but often site commenters give opinions on the topic. Other pages encompassed under informational sites include polls that ask readers their opinions on feederism. For example, a poll on missbimbo.com asked its readers, "Do feeders and feedees disgust you?", with 73\% responding yes, and $27 \%$ saying no. Other sites like urbandictionary.com and dictionary.com attempt to define 
and explain feederism. For the most part, these websites are neutral in their descriptions of feederism, but some of the polls reflect disdain for purposeful weight gain.

\subsection{Pornography}

As mentioned above, pornographic links, whether pictures, videos, or ads, represented 15 of the websites found as a result of a Google search for feederism. I distinguish feederism pornography from other photos or videos based on nudity and sexual activity (rather than merely swimsuits and eating). All of the sites depicted women, mostly alone in sexual situations, but fewer times with male partners. However, these sites were only a small portion of feederism sites I found as a whole. Particularly disturbing were two teenage feedee personal ads: one a 13 year old girl and one a teenage boy looking for a feedee of an unspecified sex. Perhaps these were adults or police officers pretending to be teens to find sexual predators on feederism websites, but I cannot say that with certainty.

Internet pornography reflects dystopian cyber feminists' claims the internet perpetuates patriarchy, perpetuating particular hegemonic definitions of sex (Hughes, 1999). It has been argued that each pornographic image of a woman on the internet can be viewed as a conquest for men who are masturbating at home (Hughes, 1999). Jensen (2007) reported that pornography makes men feel masculine, especially men who do not feel they have power in their everyday lives. Jensen stated that the ability "get back" at those women who, among other things, may have nagged them, taken over their workplaces, or refused to participate in their sexual fantasies are key reasons that men look at pornography. The woman on the screen, he argues, becomes the victim of these men's anger; is a "slut" who is asking for any sexual behavior possible. Men who view pornography may not be able to control women in their everyday lives, but in the fantasy world of pornography, women are always under their command.

Feederism pornography may be transgressive because of the images of fat women displayed on the screen. In fact, some of these women, such as Donna Simpson, who famously wanted to become the world's fattest woman, have "pay sites"; they make money off of their fat bodies (officialdonnasimpson.com). However, the end result is the same: women are sexual objects depicted for the male internet user, as Jensen (2007) might say, who may not have sexual control in his offline life. Although pornography is not the only type of feederism, as Hester (2009) suggests, feederism pornography is just another form of traditional pornography, with women of larger sizes as its stars.

\subsection{Advice}

Most of the advice websites were guides to feeders and feedees on how to gain weight quickly and (sometimes) safely. For example, many of the websites included groups to help manage the stigma that participants in feederism felt:

I was hoping to see about others out there looking to share stories for support and advice. Whatever level of enjoyment or hatred of our situation we still have to deal with outside pressures of a society that frowns upon this behavior and acceptance. I am hoping for mature discussions on this board. All are welcome I just ask that you keep it clean, mature, and real.

Yet another advice site discusses "hypnogain", the use of hypnosis to gain weight (http://www.feeder.co.uk/hypnosis.html). It does appear that the majority of these websites are trying to help people gain weight without hurting them in the short run. But, perhaps the most disturbing website I found was an advice site called Ruben's Feeder (rubensfeeder.tripod.com). This site documents Ruben's experiences feeding his partner. For Ruben, $\mathrm{H}$ and $\mathrm{K}$ cups are ideal, and he calls women's breasts "udders". He insists he likes to feed fat women, but also thin women because, in his opinion, "fat creates a bond: she and I know that is my fat, that I fed her and that she has a belly now because of me (not only, of course, she wants it as badly as I want it). This bond is really nice, because it has been shared, every new pound of jiggly lard on her has been welcomes by me as the feeder" (rubensfeeder.tripod.com). Ruben clearly believes he is in control of his partner. He has taken ownership over her body.

Theories of hegemonic masculinity (e.g. Connell and Messerschmidt, 2005) may be able to explain Ruben's ideas towards women and sex. Extreme sexual behaviors may be the mechanism by which men who are invested in these values prove their masculinity. The derogatory language and dangerous behaviors that Ruben describes demonstrate a hypermasculine need for control and power. For example, Ruben also gives advice on force feeding with tubes, why women should be feedees, and extreme feeding. He repeatedly calls a woman a pig, and tells his readers to "only do her from behind while she's eating. When she stops, you stop...a pig has no choice, it must eat!" He also encourages inserting a rubber block in the woman's mouth so she can't close her mouth, because this, to him, "extremely hot". Perhaps the most disturbing is Ruben's instructions on tube feeding directly into the stomach. He attests to the danger of this behavior, but goes on to say: 
Too much pressure and too fast is very very dangerous and causes the stomach to rupture, which means certain death, so be very very careful!!! A feeder is totally responsible for his actions after he has inserted the tube (italics added for emphasis) and needs to be careful. Just because you might have tied her down, does not mean you can do anything you want with her. There is a bond of trust between the two, you only do what you know she wants...That said, a stomach of a real pig feedee can grow to huge dimension and make her belly stick out incredible. Slowly feeding her until her navel pops inside out like a pregnant woman is so hot and many feedees orgasm when that happens (or even before).

Ruben's discussion of "trust" necessary to pull off tube-feeding does not undermine the power he has over the feedee, who may be going along with Ruben's advances because of fear of rejection. Regardless, the "choice" being made by both Ruben and his partner puts only one of them in danger. Once again, it appears that Hopkins' (1994) explanation of simulation vs. replication is limited to behaviors that are low-risk, and with extreme feeding, it is unclear when the line is between low-risk behavior and potentially deadly activity. The feedee may feel liberated to be free about her size, but has given up complete control of her body and perhaps even her life to her feeder.

Even though Rubensfeeder.com is only one website, it is the most thorough how-to guide of how to participate in life-threatening feeding acts. The content discusses control over women's bodies through dangerous practices as a sexual turn-on. This website is an example of the feederism feminists cite when they discuss it as exploitative and physically and mentally harmful towards women. Although most advice websites addressed the quickest and safest ways to gain weight, some sites encouraged dangerous behaviors.

\subsection{Links to Videos}

There were 14 websites housing links to videos. Here, there were so many that I could not separate out how many of these videos were listed more than once and how many were depicting heterosexual behaviors. In fact, a convenience sample of about 50 of these 1,494 videos found that most of the videos depicted solo bodies, whether female (as was most common) or male. None of these videos depicted pornographic situations, likely because they were housed on sites such as dailymotion.com or youtube.com. Still, the female body in underwear or swimsuit, or in the act of eating, was depicted for the arousal of male viewers. Cultural norms of beauty may be shunned, but women are still objects of pleasure for men. On the other hand, these videos may be encouraging to women of size who see others like them unafraid to show their bodies in very little clothing.

\subsection{Critical Essays}

There were ten essays defending feederism and ten essays condemning the behavior. Websites that supported feederism cited many reasons. Most common was that just like any other sexual behavior, feederism is a choice made by consenting adults. One site, linked to bigfatblog.com, discussed a feeder as a rescuer of fat women from deep depression:

His legendary feed sessions at the NAAFA conventions would make a Roman orgy look like a hunger strike. His piggies don't puke. Proud FA first plies them with booze and/or weed and lots of it. BBW's can hold their liquor unlike the feminists who hold the licker by the ears. After they let down their inhibitions the fun would begin. I would sit by while these once shrinking violets would cover Proud FA's skinny body in marshmallow, caramel syrup, M\&Ms, fudge syrup, and sprinkles and let him devour like hogs at trough.

This blog post appears to criticize the feminists who think feederism is harmful to participants. Interestingly, the blogger later reveals to be a member of NAAFA and is trying to "reform NAAFA from within" while simultaneously using derogatory language towards fat women.

This particular incident also resembles sexual assault, wearing down women's inhibitions to control them sexually, a normal part of heterosexual sex. Alcohol may be used as a tool to limit women's inhibitions and gain access to sex (Martin and Hummer, 1989; Kimmel, 1998). When alcohol is involved in sexual activity, lines of consent become blurred, and the idea that participating in feederism is a "choice" is easily refuted.

\section{Conclusion}

Previous writings on feederism argue opposite ideas about the behavior. Critics call feederism a hyper masculine activity that benefits male feeders, whereas Bestard (2009) argued that feeders and feedees are consenting adults who are not hurting anybody with private sexual acts. Up until this point, no studies had looked at the vast amount of internet content on feederism. Findings from this content analysis reveal that there are many different types of feederism websites, such as groups, advice sites, personal ads, and pornography. The content analysis also revealed that the internet is a place where fat women can find a community of similar others to support them. 
However, when it comes to feederism, men are still in control of the behavior and of how women are portrayed and treated as feedees. Although some of the websites discussed here may be advancing transgressive ideas about fat women as sexual beings, the objectification of women as sex objects is further perpetuated by these same websites. Bodies matter; normative ideas about fat women and heterosexual sex offline are perpetuated online. The internet is patriarchal as offline society. At its extreme, ideas about control over women involve manipulating their bodies using dangerous means, and the lines between consent and sexual assault are blurred. Consent is a difficult term to define in a culture where patriarchal values about sex have been internalized by members of society. Still, the internet has the potential to create loving, supportive communities for people of size rather than exploitative communities that mimic the offline world.

My research has several limitations. First, my analysis is limited to the websites that I was able to find and to which I was able to obtain access. As mentioned earlier, I had intended to conduct interviews, but members of the community were very protective of their lifestyles and did not want to give access to someone outside of their community. Second, I only paid attention to websites that promoted heterosexual relationships. I cannot draw conclusions on the nature of feederism in gay or lesbian couples.

More research needs to be performed, particularly interviews with members of these communities (the artists, the writers, thee feeders, etc.) to find out their motives. Future research should also discuss why feederism has been labeled deviant without much evidence to support such an argument.

Despite these limitations, this paper provides a thorough review of the existing literature on feederism. The paper also provides a feminist analysis of feederism in heterosexual relationships, dismissing cypertopian feminist beliefs about absence of the body on the internet. The deeper understanding of the behavior provided here may lead to less focus on the extreme forms discussed on the internet and give more insight to fat sexuality.

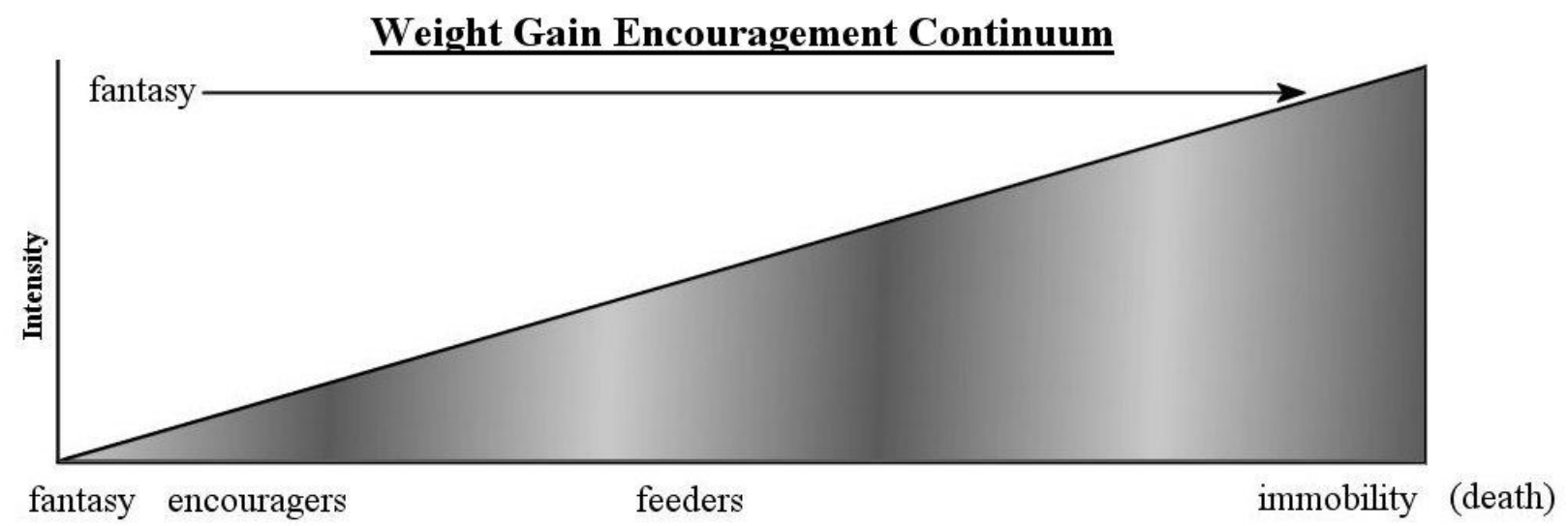

Figure 1. Bestard's Feederism Continuum

Source: Bestard, A. (2008). 'Feederism: An exploratory study into the stigma of erotic weight gain' (Master's Thesis). University of Waterloo, Waterloo, Ontario, Canada.

\section{References}

Bestard, A. (2008). Feederism: An exploratory study into the stigma of erotic weight gain (Master's Thesis). University of Waterloo, Waterloo, Ontario, Canada.

Brophy, J. E. (2010). Developing a corporeal cyberfeminism: Beyond cybertopia. New Media and Society, 12(6), 929-945. http://dx.doi.org/ 10.1177/1461444809350901

Connell, R. W., \& Messerschmidt, J. (2005). Hegemonic masculinity: rethinking the concept. Gender \& Society, 19(6), 829-859. http://dx.doi.org/10.1177/0891243205278639

Durkin, K., Forsyth, C., \& Quinn, J. F. (2006). Pathological internet communities: A new direction for sexual deviance research in a post modern era. Sociological Spectrum, 26, 595-606. http://dx.doi.org/10.1080/02732170600948857

Gauthier, D. K., \& Forsyth, C. J. (1999). Bareback sex, bug chasers, and the gift of death. Deviant Behavior, 20(1), 85-100. http://dx.doi.org/10.1080/016396299266605

Halloran, V. N. (2004). Biting reality: Extreme eating and the fascination with the gustatory abject. Iowa Journal of Cultural Studies, 4. Retrieved from http://www.uiowa.edu/ ijcs/mainstream/halloran.htm 
Hester, J. (2009, August 17). Feast of burden. Bitch, 44, 37-53.

Hopkins, P. D. (1994). Rethinking sadomasochism: Feminism, interpretation, and simulation. Hypatia, 9(1), 116-141.

Howitt, D. (1995). Paedophiles and Sexual Offences Against Children. Chichester, UK: Wiley.

Howitt, D. (2004). What is the role of fantasy in sex offending? Criminal Behavior and Mental Health, 14, 182-188.

Hughes, D. (1999). Cyber feminism: Connectivity, critique, and creativity. In S. Hawthorne \& R. Klein (Eds.), The internet and the global prostitute industry (pp. 157-184). North Melbourne, Australia: Spinifex Press.

Jensen, R. (2007).Getting Off: Pornography and the End of Masculinity. Cambridge, MA: South End Press.

Johnson, A. G. (1997).The Gender knot: Unraveling our Patriarchal Legacy. Philadelphia: Temple University Press.

Kimmel, M. S. (1998). Clarence, William, Iron Mike, Tailhook, Senator Packwood, The Spur Posse, Magic... and us. In M. E. Odem and J. Clay-Warner. (Eds.), Confronting rape and sexual assault (pp. 263-276). Wilmington, DE: Scholarly Resources, Inc.

Leitenberg, H., \& Henning, K. (1995). Sexual Fantasy. Psychological Bulletin, 117(3), 469-496.

Lillie, J. M. (2004). Cyberporn, sexuality, and the net apparatus. Convergence, 10(1), 44-65.

Martin, P. Y., \& Hummer, R. (1989). Fraternities and rape on campus. Gender \& Society, 3, 457-473.

Morahan-Martin, J. (2000). Women and the internet: Promise and perils. Cyberpsychology \& Behavior, 3(5), 683-691.

Murray, S. (2004). Locating aesthetics: Sexing the fat woman. Social Semiotics, 14, 238-247.

National Association to Advance Fat Acceptance 2011, Feederism, viewed 27 January 2011. Retrieved from http://www.naafaonline.com/dev2/about/Policies/FEEDERISM.pdf

Plant, S. (2000). On the matrix: Cyber feminist simulations. In D. Bell \& B. M. Kennedy (Eds.), The Cybercultures Reader (pp. 325-336). New York, NY: Routledge.

Note 1: My goal was to supplement this project with interviews with women and men who described themselves as feeders and feedees. I had joined FantasyFeeder.com and Dimensionsonline.com in order to gain access to discussion groups where I could post recruitment ads. These ads would disappear a few hours after posting, and I only received one response from an interested partyduring the one-year period of conducting this study.

\section{$(\mathrm{cc}) \mathrm{BY}$}

This work is licensed under a Creative Commons Attribution 3.0 License. 